\title{
Estampas de tradução e cultura visual A imagem impressa e a formação da cultura visual no Rio de Janeiro, século XIX
}

\author{
Marianne Farah Arnone ${ }^{1}$ \\ DOI 10.20396/eha.vil4.3328
}

O que seriam estampas de tradução?

Tradução, interpretação e reprodução são termos utilizados para definir as estampas que são realizadas a partir da transposição de obras de arte, ou seja, aquelas que transpõem para as diferentes técnicas gráficas pinturas, desenhos, esculturas, monumentos arquitetônicos e outras gravuras.

Em seu ensaio Sobre o valor crítico da gravura de tradução², o estudioso italiano Giulio Carlo Argan utiliza o termo tradução para definir esse tipo de gravura. Ele entende que o ato de transpor uma obra de arte para a gravura é mais do que um mero processo de reprodução, por tal motivo utiliza o termo gravura de tradução. Ao transferir uma obra para a gravura, o gravador realiza um processo de tradução, o que confere uma dimensão crítica à estampa elaborada. $O$ autor ressalta que não se trata de uma cópia ou réplica do original, pois o procedimento técnico realizado é completamente diverso, utilizando outros elementos, materiais e suportes para obter um resultado de equivalências de valores com a obra original. Desse modo, a estampa de tradução apresenta características específicas que impactam a leitura, a recepção e a contemplação de modo diverso que o contato com o original ${ }^{3}$. Por compartilharmos dessa concepção sobre essas estampas daremos preferência ao emprego do termo tradução no decorrer do texto.

Em seu ensaio, Giulio Argan aponta que desde o século XVI artistas utilizaram a gravura como um meio de multiplicarem suas obras e se tornarem mais conhecidos. Artistas como Rafael, Leonardo da Vinci, Rubens entre outros possuíam intérpretes para traduzirem suas obras para a gravura. Argan defende que o desenvolvimento e hegemonia da tradição artística europeia não se-

\footnotetext{
1 Esta publicação faz parte da pesquisa de doutorado em andamento orientada pelo Prof. Dr. Domingos Tadeu Chiarelli, desenvolvida no Programa de Pós-Craduação em Artes Visuais; no Departamento de Artes Visuais da Universidade de São Paulo. A pesquisa conta com financiamento da Coordenação de Aperfeiçoamento de Pessoal de Nível Superior - Brasil (CAPES) - Código de Financiamento 001. 
riam possíveis sem a reprodução das obras de artes, primeiro pela gravura e, então, pela fotografia. Argumenta que a consagração de obras, estilos e artistas, assim como a afirmação de um gosto pelas belas artes e a formação de uma visualidade, de uma cultura visual na Europa, estão, em grande medida, comprometidas com a reprodução da arte pela gravura.

A estampa de tradução não é, portanto, um fenômeno do século XIX. Entretanto, alguns fatores tornam o século XIX um período interessante para se pensar essas estampas. Foi um momento de grandes desenvolvimentos técnicos e de inovações no campo da gráfica, como a prensa cilíndrica e rotativa, o papel em bobinas e o linotipo. Inovações como o desenvolvimento dos processos de estereotipia, os aperfeiçoamentos nas técnicas gráficas como a xilografia de topo e a litografia para uso industrial, a fotografia e os processos fotomecânicos possibilitaram a produção de imagens e publicações em grande escala, assim como o desenvolvimento da imprensa ilustrada.

As estampas de tradução e o século XIX

O século XIX vivenciou um grande crescimento no consumo de estampas gráficas dedicadas à reprodução de obras de arte, o que dinamizou o comércio internacional desse tipo de imagem. Na Europa surgem casas especializadas na venda de estampas, como a consagrada e pioneira Coupil $\delta$ Cie fundada em 1829 em Paris, e que vendiam gravuras impressas com técnicas variadas e exportavam reproduções para vários países, como o Brasil. O público europeu adquiria a prática de comprar e colecionar estampas, lançando modas e estimulando o comércio de imagens. Jornais e revistas anunciavam a venda de gravuras reproduzindo as últimas pinturas dos artistas vencedores no Sa$10 n^{4}$.

Multiplicavam-se as publicações repletas de ilustrações gráficas e que tinham entre suas propostas a divulgação dos temas artísticos, tais como o Illustrated London News (Londres, 1842), The pictorial times (Londres,1843-48); L'illustration (Paris, 1943-44); Illustrirte Zeitung (Berlim,1843-44); O panorama (Portugal, 1837-1868); a Revue des Deux-Mondes (Paris, 1829-1944), entre outros. Os periódicos ilustrados tornam-se, no século XIX, um espaço importante para a discussão e difusão das artes. A imprensa possui um papel fundamental para compreendermos o crescimento e o consumo de imagens, entre elas as imagens traduzindo obras de artes. Jornais e revistas ilustrados ampliavam a circulação e o alcance dessas imagens. O especialista no estudo da gravura na Europa, Stephen 
Bann, cita o protagonismo da imprensa francesa e inglesa na produção de revistas e suplementos ilustrados, criando publicações que se espalharam para diversas regiões e lançaram modelos e padrões de impressos ilustrados 5 .

Rio de Janeiro e as estampas de tradução

No Brasil, também se observa, nesse momento, sobretudo na segunda metade do século, o desenvolvimento da indústria gráfica e o aumento na circulação de estampas. Estas podiam ser encontradas tanto avulsas, comercializadas em tipografias, livrarias e estabelecimentos de molduras e vidro como também impressas nos livros e nos diversos periódicos. Jornais e revistas passam a publicar gravuras de obras de arte dedicando textos especificamente às ilustrações e dando destaque a elas. Também passam a oferecer aos assinantes os Suplementos, estampas encartadas, e ainda publicavam anúncios de vendas de gravuras e os locais onde seria possível encontrá-las ${ }^{6}$.

Entre as publicações que circulavam no Rio de Janeiro e que traziam imagens gráficas de obras artísticas encontramos as revistas: Museu Universal (R], 1837-1844); Revista Ilustrada (R],18761898); A Estação (RJ,1879-1904); A Vida Fluminense (R],1868-1874); Jornal das Famílias (R],1863-1878); e Semana Ilustrada(R],1861-1875); O Brasil Ilustrado (R],1887); O Guarani (R],1871); Ilustração Brasileira (R],1876-1878); Diário Ilustrado (R],1880-1889); A llustração (Paris, 1884-1892), entre outras. (fig.01)

A imprensa é fundamental para analisarmos as estampas de tradução e seus vínculos com a cultura visual do período. Isso, uma vez que, além de diversos periódicos possuírem imagens de obras de arte e terem como proposta a divulgação dos temas ligados às artes, também possuíam artigos e anúncios sobre a venda de gravuras e publicações ilustradas com obras de arte. (fig.02/03/04)

O século XIX foi um período de produção e consumo intenso de imagens e a imprensa desempenhou um papel significativo na divulgação de obras e temas artísticos. Como apresentado, o Rio de Janeiro não ficou alheio a esse fenômeno e, na segunda metade do século, observa-se a circulação de diversas publicações ilustradas que tinham entre suas propostas temas ligados à arte e imagens de obras de arte.

Mas como comprovar que esse material foi relevante e estava sendo, de fato, absorvido pelo público e impactando na cultura visual da sociedade carioca? 

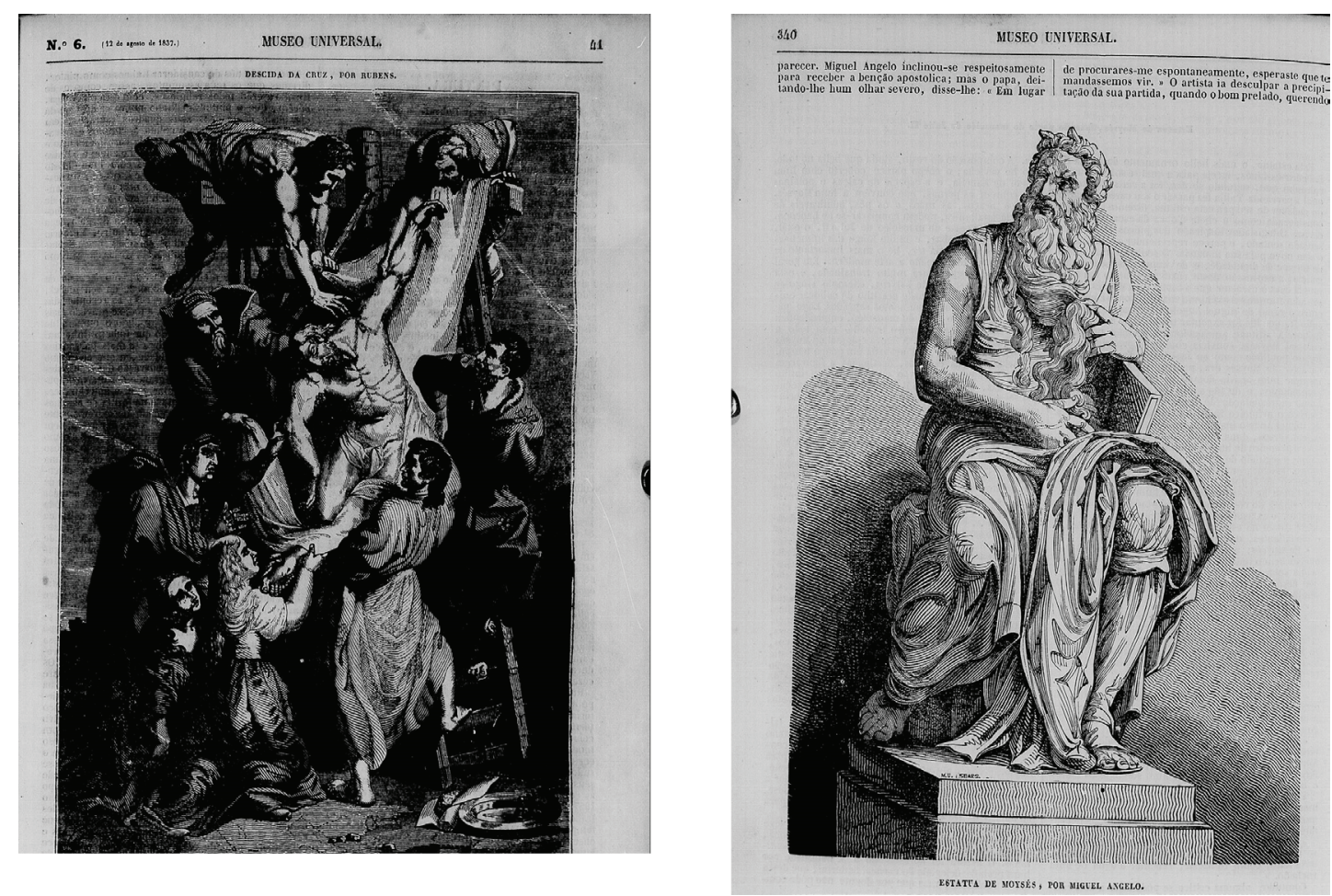

[Figura 01] Páginas do Museu Universal traduzindo a escultura Moisés a partir de Michelangelo e traduzindo a pintura Descida da Cruz a partir de Rubens.
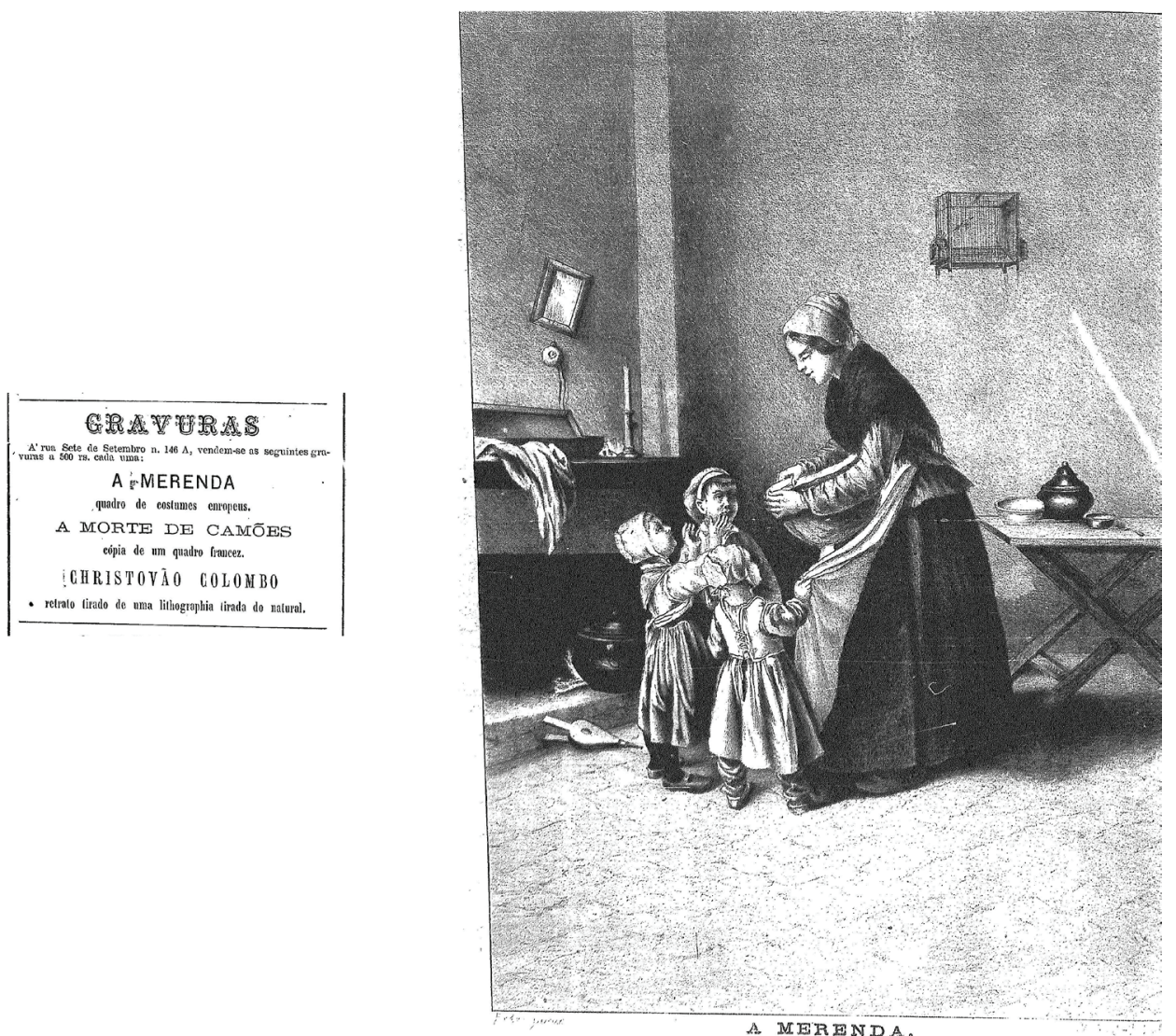

[Figura 02] Anúncio da venda de gravuras e a estampa reproduzindo o quadro A merenda publicada no periódico Guarani, Rio de Janeiro, 1871. 

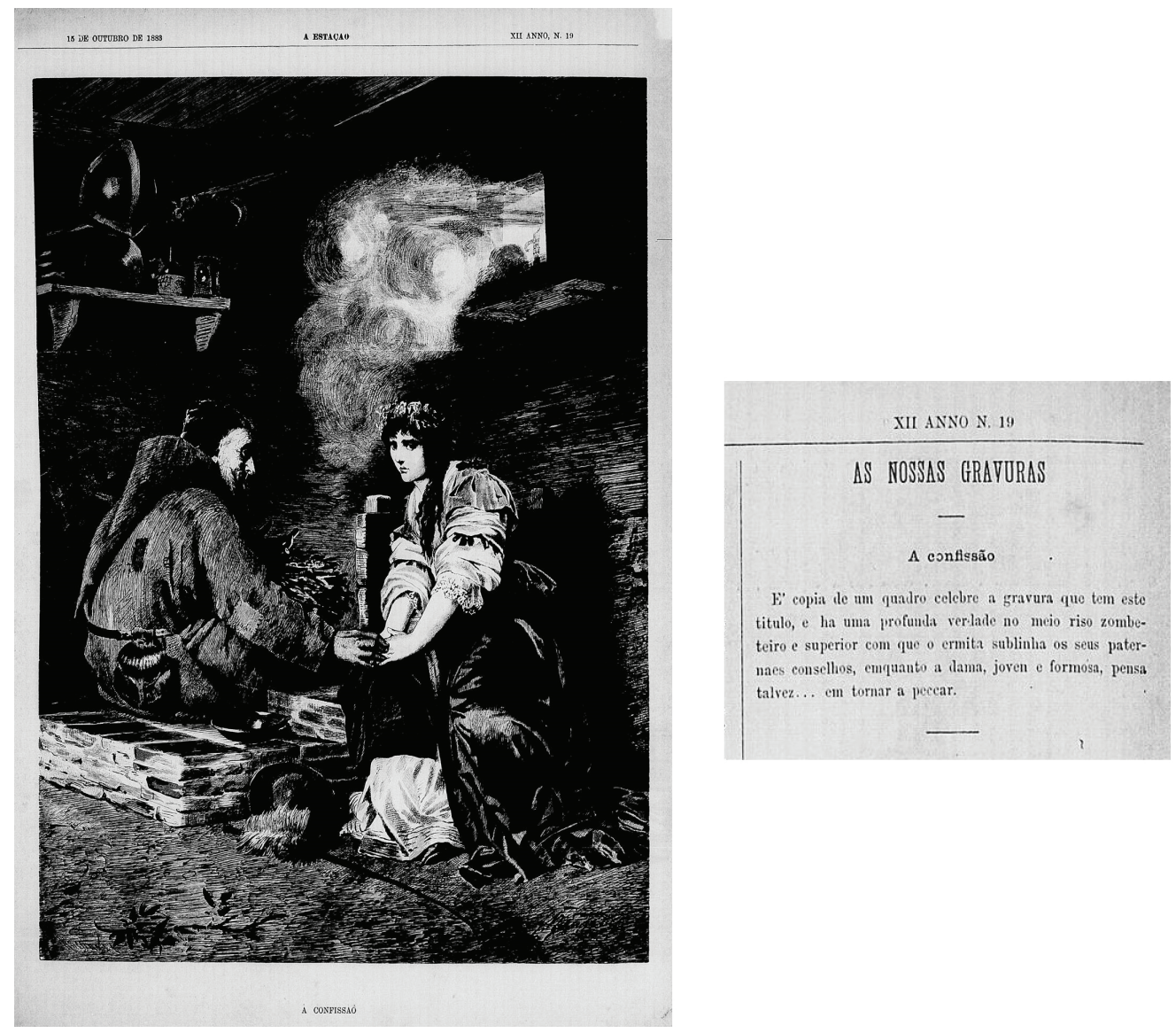

[Figura 03] Gravura reproduzindo A confissão e legenda explicativa publicada no periódico A Estação.

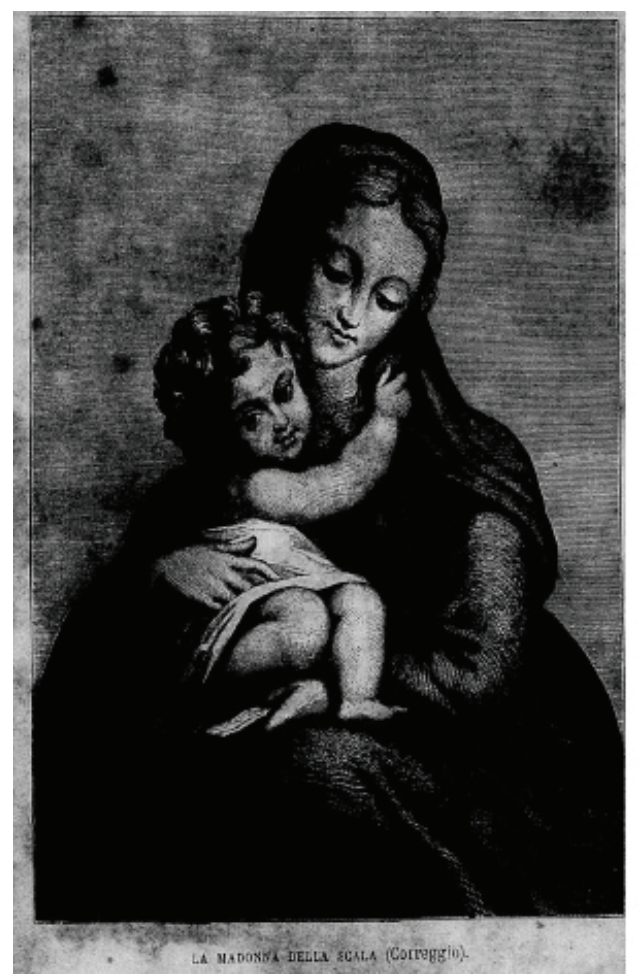

\section{A MADONA (DELLA SCALA).}

GRAVERA SOEAE YADEIRA.

A linda gravura que ollerecemos ás nossas assignantes, é a copia exactisAima do admirarel quadro conhecido pelo nome de Madona della Scala. Esse painel que faz parte do Muséo de Parma, é uma das primeiras obras de Corregio, afamado pintor italiano que o executou em 1516.

[Figura 04] Legenda e gravura reproduzindo Madonna della Scala (Correggio) publicada no periódico Jornal das Famílias 
O fato de parte das publicações, que dependiam dos assinantes para sua sobrevivência, resistirem a um longo período de duração, já é um indicativo de que possuíam um público que alimentava uma demanda. Mas como compreender e detalhar melhor essa demanda de modo a analisar suas repercussões na produção artística e na vida cultural da sociedade carioca oitocentista?

Um meio de perceber o modo como as estampas de tradução estavam impactando a cultura visual é a análise dos textos e da literatura produzida no período. Este tópico é fundamental, porém será apenas destacado como uma fonte de relevância e não será desenvolvido neste momento. No texto, nos deteremos a apresentar dois casos significativos no sentido de estimular a reflexão do tema: o primeiro será apresentar a coleção do escritor Artur Azevedo que possuía um volume expressivo de estampas de tradução extraídas de suplementos, jornais e revistas e que foi o tema central da tese de Frederico Silva (2016). O segundo será expor os diálogos envolvendo uma estampa de tradução publicada na revista A Ilustração e a tela Arrufos, de Belmiro de Almeida, que foram analisados pelo estudioso Arthur Valle.

Estampas retratadas em textos, notícias de jornal e na literatura

As descrições que evidenciam a presença das estampas de tradução no cotidiano da sociedade carioca oitocentista presentes nos textos, artigos, notícias, anúncios de jornais e na literatura do período, demonstraram ser elementos importantes para se detectar a recepção do público e o impacto dessas imagens na cultura visual do período. Os periódicos, além de se constituírem como objetos de estudo fundamentais no que diz respeito à pesquisa, identificação e levantamento de imagens traduzindo obras de arte, também demonstram potencial de investigação sobre o tema por meio de seus textos, artigos, folhetins e anúncios. Neste sentido, também a literatura do período se apresenta como um material importante para a investigação, pois possui muitas referências sobre o consumo e a presença das imagens reproduzindo obras de arte no cotidiano da sociedade carioca oitocentista.

A partir da leitura dos trechos de obras literárias do período observamos a presença do consumo de imagens como parte do cotidiano das personagens, demonstrando o quanto eram presentes e significativas para a cultura visual oitocentista. Neste sentido, percebemos muitas citações e referências às imagens gráficas e aos jornais ilustrados ${ }^{7}$. Nos textos literários observamos várias re-

7 CHIARELLI, pesquisa inédita. 
ferências visuais que faziam parte do cotidiano e da decoração das casas dos personagens como, por exemplo, os retratos, os cromos e álbuns fotográficos, quadros, estatuetas, oleografias, gravuras, os livros e jornais ilustrados, o que demonstra o quanto esses objetos e imagens são significativos para compreensão da "cultura material e visual" do Brasil oitocentista.

\section{O caso da coleção de Artur Azevedo}

Conforme apontado, os jornais do período apresentam descrições que nos possibilitam compreender melhor a presença e as práticas envolvendo as estampas de tradução. Um exemplo, neste sentido, relacionado às imagens de tradução e seus vínculos com o desenvolvimento do colecionismo e a cultura visual do período, seriam os textos publicados na coluna De Palanque do jornal Diário de Notícias em duas ocasiões, em setembro de 1885 e em março de 1887. A coluna assinada por Eloy, O heróe, pseudônimo de Artur Azevedo, apresenta indícios interessantes para se pensar a presença das estampas de tradução nas coleções de arte no Rio de Janeiro desse período.

Na coluna de 1885, o autor narra um episódio que supostamente teria ocorrido com o artista Aurélio Figueiredo. Este, ao ser convidado a ir à casa de um fidalgo para conhecer sua coleção de arte, surpreende-se ao perceber que as tais preciosidades artísticas não passavam de "infelizes cromos e oleografias":

Imagine o leitor a cara que fez o Aurélio, quando descobriu uma coleção infeliz de oleografias e cromos, desses que o leitor, se é homem de bom gosto, não consentiria em sua casa, nem mesmo que lhe pagassem direitos de armazenagem ${ }^{8}$.

No outro episódio, apresentado na coluna De Palanque de 1887, o autor descreve o caso em que o pintor Pedro Américo faz um comentário a um deputado sobre uma oleografia exposta na parede:

Pedro Américo, há coisa de um ano, contou-me que, achando-se nesta Corte de visita em casa de um deputado geral, que se dizia grande amador de pintura, deu com os olhos em uma oleografia pendurada na parede. Era a reprodução de um bonito quadro, italiano, representando uma formosa mulher loira, de mãos postas e olhos erguidos para o céu, rezando, creio. O leitor deve conhecer essa oleografia, que é encontrada em toda parte. Pedro Américo abanou a cabeça e disse:

- o autor daquele quadro vendeu-o ao Estado por tantas mil liras (não posso precisar a

8 Diário de Noticias, Rio de Janeiro, 1885, p.01. 
quantia).

O deputado deu pulo e exclamou:

-Oh! Diabo! Nesse caso, fiz uma pechincha! Comprei-o por trinta e cinco mil reis!?.

Nesses episódios, Artur Azevedo apresenta sua opinião sobre a falta de conhecimento e gosto duvidoso dos colecionadores de arte no Rio de Janeiro e se refere ao que ele entendia como a baixa qualidade de suas coleções, repletas de reproduções. Esses trechos trazem elementos interessantes para se pensar a cultura visual e ressaltam a presença dessas imagens nas coleções particulares do período.

As cromolitografias e oleografias, mesmo não sendo, de maneira geral, publicadas no interior de jornais e revistas, eram frequentemente ofertadas aos assinantes como suplementos, anunciadas como recompensa por adesão à assinatura e tinham sua venda divulgada nos anúncios e publicidades dos jornais. Possuem, desse modo, vínculos diretos com a imprensa e as publicações ilustradas.

O próprio Artur Azevedo possuía esse tipo de estampa em sua coleção, como demonstra a pesquisa de Frederico Sousa Silva sobre o tema ${ }^{10}$. Azevedo iniciou sua coleção no Rio de Janeiro no final do século XIX e reuniu em seu acervo pinturas, livros, revistas, mas se dedicou, sobretudo, a colecionar estampas gráficas. Grande parte dessas imagens eram suplementos de jornais e revistas, ou seja, eram estampas encartadas em periódicos ilustrados do período, como é o caso da xilogravura de D. G Anderson traduzindo a tela A Primeira Missa no Brasil (1860), de Vitor Meirelles, encartada no periódico Echo Americano (1871-1872) ${ }^{11}$. As gravuras possuem uma função de destaque para a compreensão da coleção de Azevedo e oferecem elementos interessantes para a investigação sobre o papel das imagens impressas na cultura visual oitocentista. (fig.05/ fig.06)

O objetivo, neste momento, foi expor o caso da coleção de Azevedo como um exemplo significativo no sentido de se pensar a presença e o modo como estampas estavam integrando a cultura visual do período. Isso, uma vez que é sintomático que parte expressiva da coleção de Azevedo, intelectual bastante ativo no final do século XIX, fosse constituída por esse tipo de imagem.

\footnotetext{
9 Diário de Notícias, Rio de Janeiro, 1887, p.o1.

10 A aparente contradição de Artur Azevedo em criticar a presença de estampas de tradução nas coleçães particulares e ao mesmo tempo possuir uma quantidade expressiva delas em sua própria coleção precisa ser mais investigada.

11 SILVA, 2016.
} 


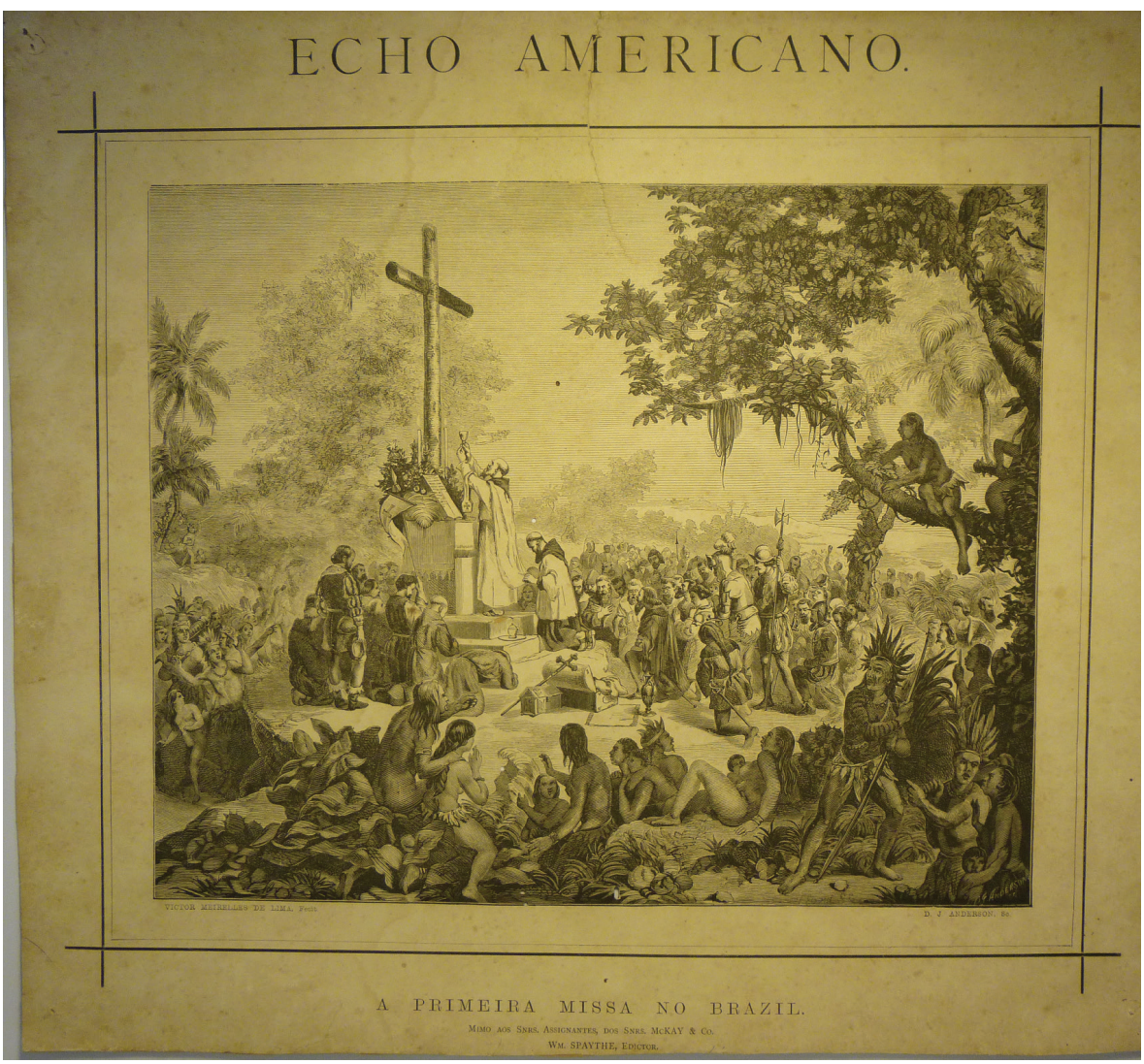

[Figura 05] Xilogravura pertencente ao acervo da Coleção Arthur Azevedo (São Luís, MA). A estampa é uma tradução realizada pelo gravador D. G Anderson da tela A Primeira Missa no Brasil (1860) de Victor Meirelles encartada pelo periódico, Echo Americano (1871-1872).

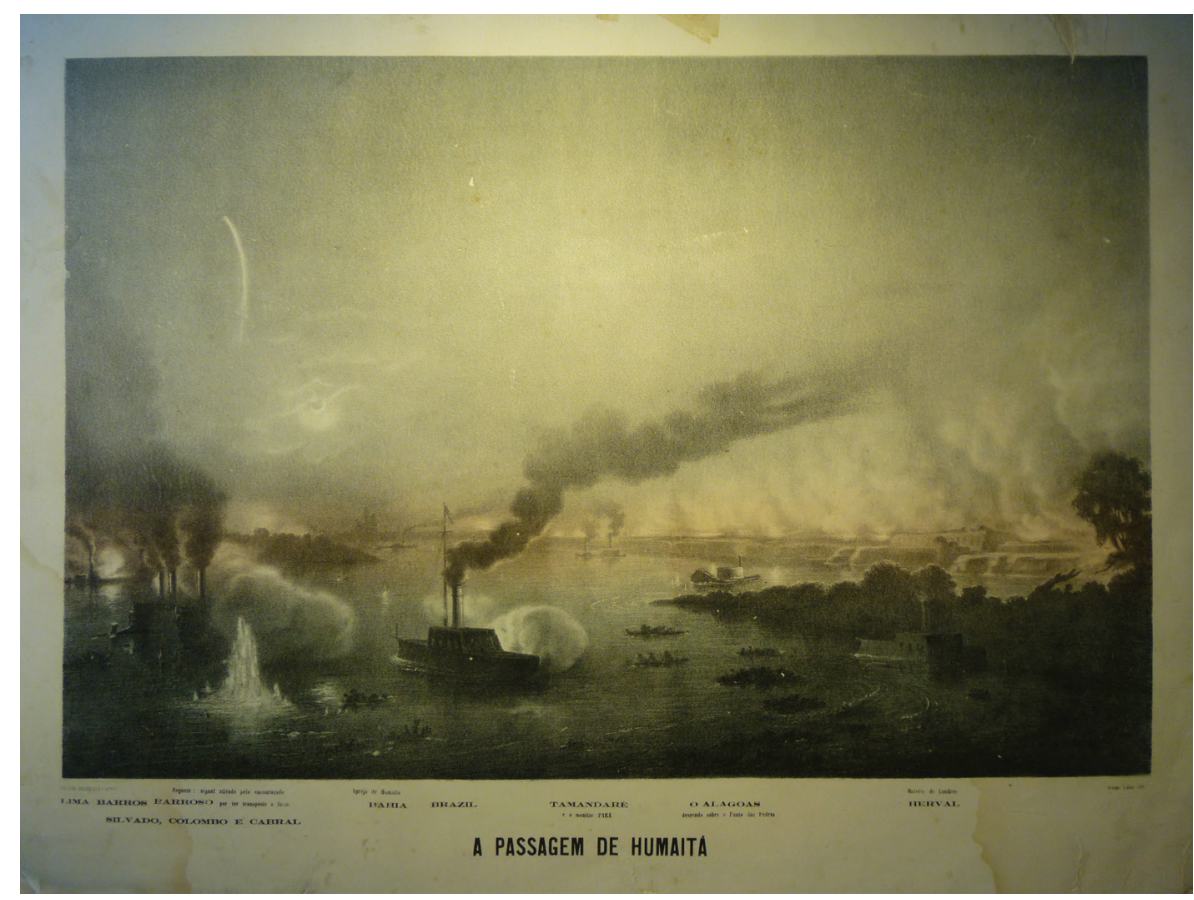

[Figura 06] Cromolitografia pertencente ao acervo da Coleção Arthur Azevedo (São Luís, MA). A estampa é uma tradução realizada pelo litógrafo Souza Lobo da pintura A Passagem de Humaitá de Victor Meirelles publicada como suplemento da Vida Fluminense. 


\section{O caso Belmiro de Almeida e a tela Arrufos}

No que diz respeito ao caso específico dos vínculos estabelecidos entre os artistas e as reproduções publicadas nos periódicos, traremos como exemplo o caso de Belmiro de Almeida e sua obra, Arrufos (1887), analisado por Arthur Valle no artigo, On Active Reception and Parody: Belmiro de Almeida's “Arrufos" (Lovers' Quarrel) (2015). No artigo, Arthur Valle chama atenção para os diálogos estabelecidos entre a obra, Arrufos, de Belmiro de Almeida, e uma estampa traduzindo a tela, Retour du bal (1885), do artista francês Henri Gervex e que foi publicada na revista A Ilustração que circulou em maio de 1885.

Antes de analisarmos o caso seria importante fazermos algumas considerações sobre a revista A Ilustração. O periódico era uma produção envolvendo Brasil, Portugal e França e buscava o intercâmbio cultural e de notícias entre esses três países. O foco da revista era trazer temas ligados à cultura como as belas artes, a literatura, teatro, música, moda, sendo repleta de ilustrações e estampas reproduzindo obras de arte. A revista era editada e impressa em Paris que, assim como Londres, se destacava como uma referência para a indústria gráfica. O diretor da publicação era o jornalista e editor português Mariano Pina que tinha contato com diversos artistas e intelectuais do período ${ }^{12}$.

No episódio envolvendo o artista Belmiro de Almeida, Arthur Valle defende a ideia de que o artista possivelmente teve acesso à gravura traduzindo a tela de Gervex publicada na revista, A Ilustração, antes da produção de sua própria tela, Arrufos. Isso, segundo o autor, teria impactado tanto a produção como a recepção da obra de Belmiro naquele momento:

(...) como a revista teve uma circulação significativa entre as elites portuguesas e brasileiras, Belmiro podia ter certeza de que o diálogo que Arrufos estabeleceu com o Retour du bal não passaria despercebido pelo público brasileiro. Portanto, a existência de uma comunidade de significado estabelecida anteriormente pode explicar pelo menos parte do sucesso que Arrufos obteve no Brasil. A recepção da pintura foi muito positiva quando foi exibida pela primeira vez no Rio de Janeiro em agosto de 1887; em 1888, o pedido de Belmiro de que Arrufos fosse comprado pelo governo imperial brasileiro para a galeria da Academia de Belas Artes do Rio foi aceito. Ainda em 1888, Conzaga Duque afirmou que "até agora uma pintura tão importante quanto essa não havia sido produzida no Rio de Janeiro" ${ }^{13}$.

A obra, Arrufos, recebeu grande destaque quando apresentada ao público, sendo ressaltada

\footnotetext{
12 DE LUCA, 2018.

13 VALLE, online.

Tradução de minha autoria.
} 
pela imprensa e valorizada nos textos críticos de Conzaga Duque, Ângelo Agostini e Félix Ferreira.

Com relação à produção da tela de Belmiro de Almeida, Arthur Valle defende que mais significativo que a semelhança entre os temas e de certos elementos compositivos presentes nas obras de Belmiro e Gervex, são os elementos que as difere:

Arrufos é sem dúvida uma pintura muito sexista; mas acho que merece atenção em relação ao que parece ser sua resposta irônica a outra forma de dominação - implícita nas relações artísticas centro- periferia. Portanto, em vez de enfatizar as evidentes semelhanças de tema e composição entre Arrufos e Retour du Bal, aqui gostaria de discutir o trabalho de Belmiro como um exemplo de como a circulação de significados culturais entre centros e periferias geralmente não leva à homogeneização, mas para um processo dinâmico de empréstimos, reinvenções e ressignificações, geralmente na forma de paródia ${ }^{14}$.

O autor sugere que Belmiro, sabendo a repercussão e o impacto que a gravura causaria no público, sobretudo na elite luso-portuguesa, desenvolveu sua obra de modo a dialogar com a tela do artista francês conferindo um tom paródico: "Arrufos é uma espécie de paródia de Retour du bal: o que Gervex trata de maneira melodramática, Belmiro reduz à trivialidade de uma discussão comum"15.

Outro ponto ressaltado por Arthur Valle em seu artigo e que merece realce é a aproximação de Belmiro de Almeida com o editor da revista A Ilustração, Mariano Pina. O artista se correspondia com Pina solicitando, por meio de cartas, que o editor publicasse certos textos e imagens na revista, demonstrando que Belmiro percebia o impacto e a repercussão que a publicação causava no público e na cena artística do período. Os vínculos estabelecidos entre artista e editor são interessantes para se pensar o papel e importância da imprensa ilustrada para a composição da cultura visual oitocentista. Todas essas questões suscitam reflexões para compreender melhor as relações dos artistas com os periódicos e o impacto das publicações ilustradas com reproduções de obras de arte na produção artística da segunda metade do século XIX. (fig.07/ fig.08)

Os dois casos apresentados e utilizados como exemplos buscam demonstrar o potencial do estudo das estampas de tradução no sentido de se analisar a cultura visual ligada às artes no Rio de Janeiro na segunda metade do século XIX. 


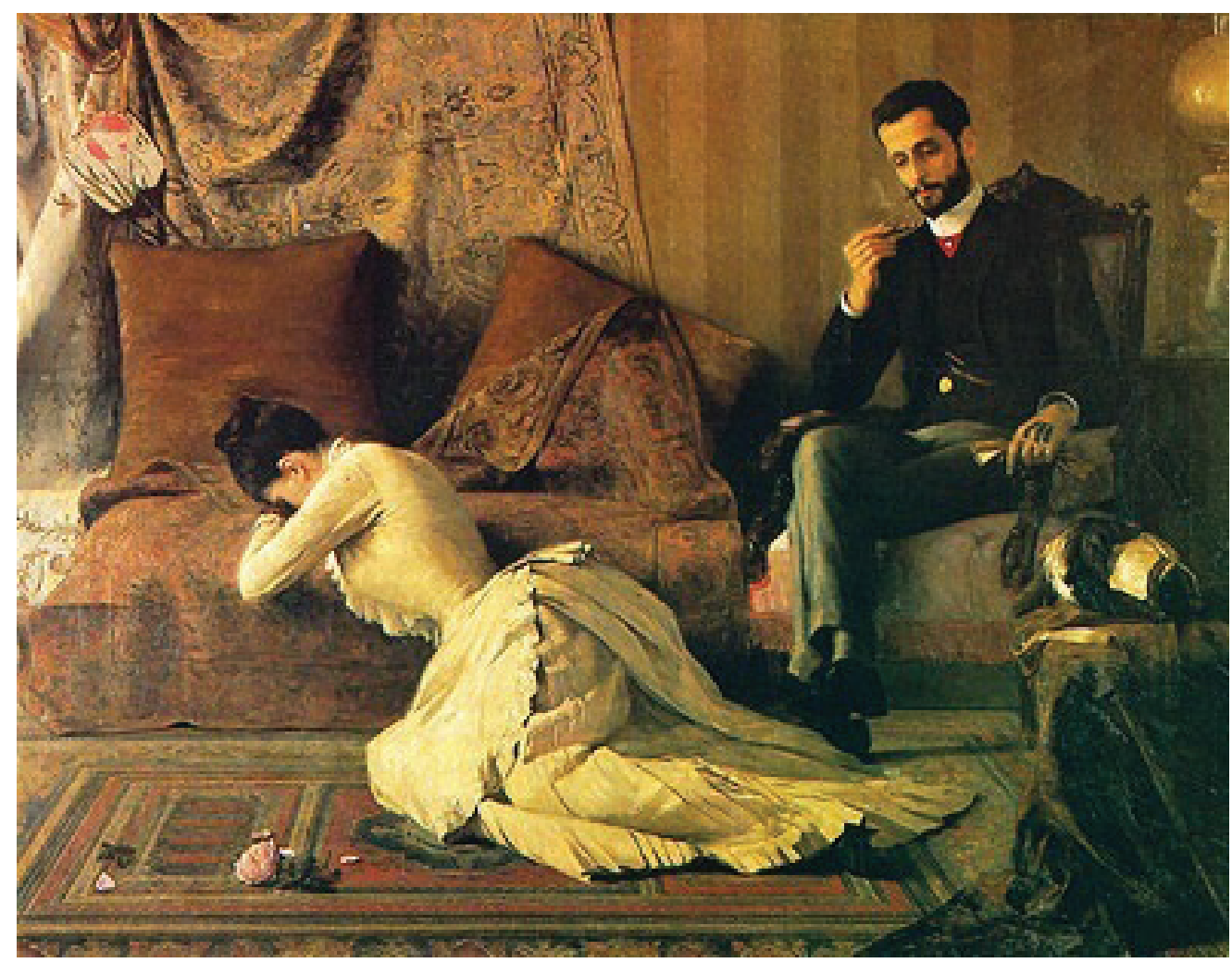

[Figura 07] Belmiro de Almeida, Arrufos, 1887.

Óleo sobre tela, $89 \times 116 \mathrm{~cm}$, Museu Nacional de Belas Artes, Rio de Janeiro.

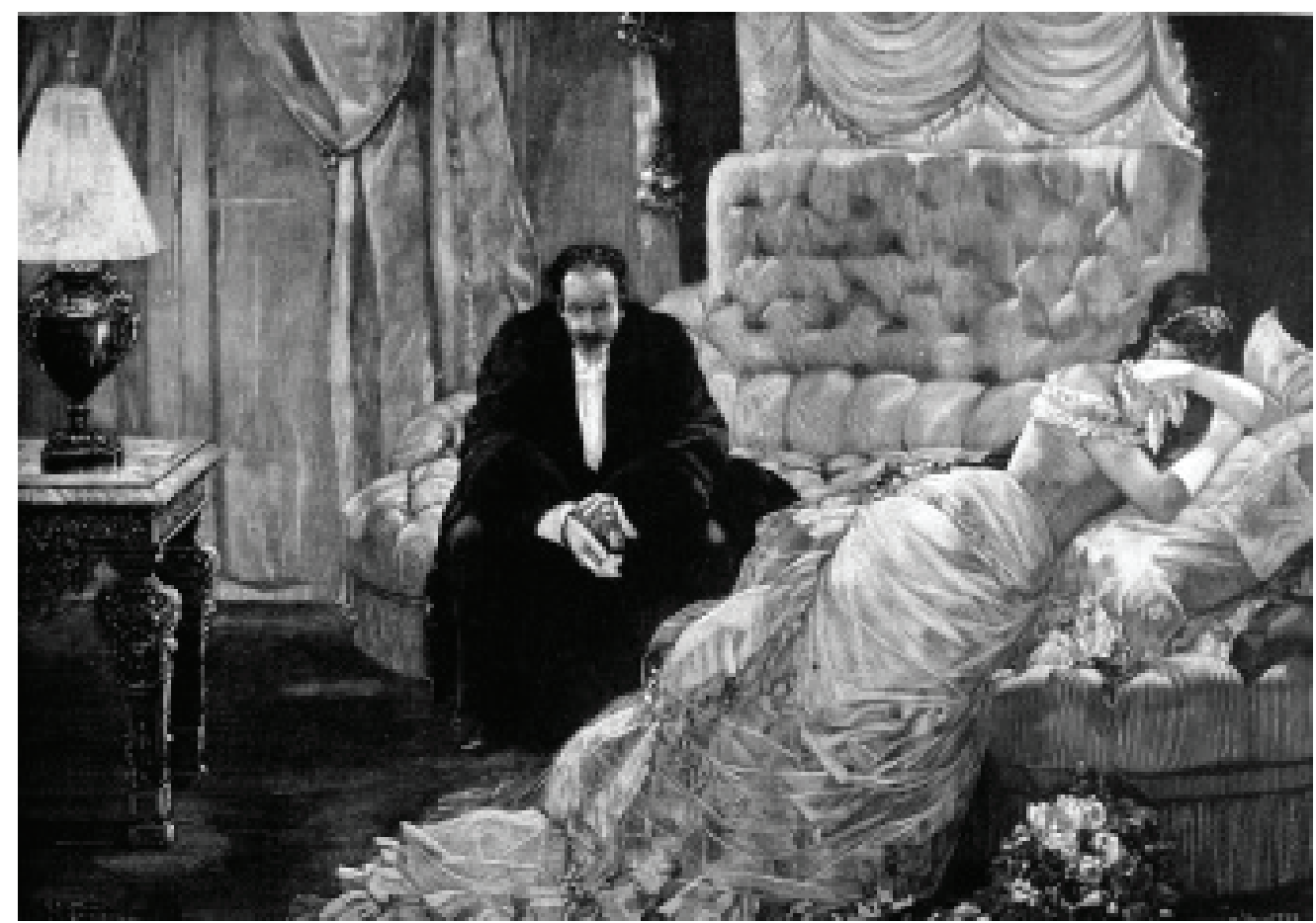

[Figura 08] Gravura traduzindo a pintura, Depois do Baile, de Henri Cervex publicada na Revista llustração na edição de maio de 1885. 


\section{Referências Bibliográficas}

ANDRADE, Joaquim Marçal Ferreira de. História da Fotorreportagem no Brasil/ A Fotografia na Imprensa do Rio de Janeiro de 1839 a 1900. Rio de Janeiro: Edições Biblioteca Nacional, 2004.

ARCAN, Giulio Carlo. 0 valor crítico da estampa de tradução - (in.) Imagem e persuasão: ensaios sobre o barroco. Tradução Maurício Santana Dias. São Paulo: Companhia das Letras, 2004.

BANN, Stephen. Distinguished Images. Prints and the Visual Economy in Nineteenth-century France. Yale Press, 2013.

CHIARELLI, Tadeu. As artes visuais na literatura brasileira do século XIX. Pesquisa inédita.

DENIS, Rafael Cardoso. Uma introdução à história do design. São Paulo: Edgard Blucher, 2010. (org.). O Design Brasileiro: antes do design. São Paulo: Cosac\&Naify, 2005

Projeto gráfico e meio editorial nas revistas ilustradas do Segundo Reinado (In). KAUSS, Paulo; MALTA, Marize; OLIVEIRA; Cláudia de; VELLOSO, Mônica Pimenta . REVISTAS ILUSTRADAS - Modos de Ler e Ver no Segundo Reinado. Editora Mauad, Rio de Janeiro, 2011.

ELOY, O herói. Palanque. Diário de Noticias, Rio de Janeiro, 1885.

Palanque. Diário de Noticias, Rio de Janeiro, 1887.

FERREIRA, Orlando da Costa. Imagem e Letra. Introdução à bibliologia brasileira. A imagem gravada. São Paulo: Edusp, 1994.

LAFONT-COUTURIER, Hélène. La maison Goupil ou la notion d'oeuvre originale remise en question. In: Revue de I'Art, 1996, n'112.

LUCA, Tania Regina de Luca. A Ilustração (1884-1892). Circulação de textos e imagens entre Paris, Lisboa e Rio de Janeiro. Editora Unesp, São Paulo, 2018.

NAIFEH, Steven; SMITH, Gregory White Smith. Van Gogh. Companhia das Letras; Edição: 1ª , São Paulo, 2012.

SILVA, Frederico Fernando Souza. Arthur Azevedo: o crítico de arte como colecionador/ o colecionador como crítico de arte Tese Doutorado, Universidade de São Paulo ECA-USP, 2016.

VALLE, Arthur. On Active Reception and Parody: Belmiro de Almeida's “Arrufos” (Lovers' Quarrel). 2015. Online. . Transnational Dialogues in the Images of A llustração, 1884-1892. Online. 